\title{
DEGENERATIVE CHANGES IN THE RAT VISUAL PATHWAY WHEN THIAMIN AND RIBOFLAVIN DEFICIENCIES ARE COMBINED*
}

BY

\section{F. C. RODGER}

From the Department of Physiology, Medical School, University of Durham

Ir was shown by the author in a recent paper (Rodger, 1953) that when thiamin deficiency in rats is of moderate degree and prolonged for about 6 months, degeneration of the visual pathway develops in certain of them. The dosages of thiamin used in the deficiency and control groups, which were not very clearly given in the earlier paper, are repeated in the present study, which deals with the effect on rats of combining thiamin and riboflavin! deficiencies.

Choice of Diet.-In selecting what is described as the "Stock" diet in this and the previous paper, trials were performed with casein, salt, and the fat-soluble vitamins as constants, and the following variants:

(1) Glucose and the synthetic water-soluble vitamins,

(2) Glucose and autoclaved yeast,

(3) Dextrinized starch and the synthetic water-soluble vitamins,

(4) Dextrinized starch and autoclaved yeast.

The effectiveness of these diets in producing signs characteristic of thiamin deficiency after 6 weeks is shown in Table A, where it is seen that the diet which incorporated glucose and the synthetic water-soluble vitamins was the most successful in producing a deficiency. This also happened to be the one most easily prepared. The water-soluble vitamins and the two thiamin solutions mixed more readily with the glucose-casein base than with the starch-casein. It was suspected that some of the vitamin was lost in the latter mixture, but there appeared to be little likelihood of this happening with the fine dry glucose-casein powder which readily adsorbed moisture.

TABLE A

EFFECTIVENESS OF FOUR DIFFERENT THIAMIN DEFICIENCY DIETS

\begin{tabular}{c|c|c|c|c|c|c|c}
\hline $\begin{array}{c}\text { Diet } \\
\text { (6 Rats) }\end{array}$ & $\begin{array}{c}\text { Mean Heart } \\
\text { Rate (beats/ } \\
\text { min.) }\end{array}$ & $\begin{array}{c}\text { Mean Temp. } \\
\left({ }^{\circ} \text { F.) }\right.\end{array}$ & $\begin{array}{c}\text { Mean } \\
\text { Wt. (g.) }\end{array}$ & $\begin{array}{c}\text { Loss or } \\
\text { Gain }\end{array}$ & Inco-ordination & Spasticity & Death \\
\hline 1 & $183 \cdot 3$ & $97^{2}$ & $-22 \cdot 6$ & 0 & 5 severe & 5 & 2 \\
\hline 2 & $378 \cdot 0$ & $97^{4}$ & $-13 \cdot 6$ & 1 gain & 5 slight & 0 & 0 \\
\hline 3 & $366 \cdot 6$ & $98^{1}$ & $-19 \cdot 0$ & 0 & 5 moderate & 1 & 2 \\
\hline 4 & $390 \cdot 1$ & $98^{3}$ & $+2 \cdot 4$ & 3 losses & none & 0 & 0 \\
\hline
\end{tabular}

*Received for publication September 9, 1953. 
Administration of Thiamin.- Thiamin (full) was the term used to describe the solution of thiamin hydrochloride given to the control rats in all our experiments, both in this series, and in the series described in the earlier paper. $1 \mathrm{ml}$. contained $500 \mu \mathrm{g}$. thiamin hydrochloride. This was the daily dose in the paired control animals; a huge one, it must be admitted.

Thiamin (minimal) was the term used to describe the solution of thiamin hydrochloride administered in the deficiency experiments. $1 \mathrm{ml}$. contained $10 \mu \mathrm{g}$. thiamin hydrochloride. The daily dose has varied, averaging about $0.5 \mathrm{ml}$. In the present experiments, an attempt was made to give the dose according to a preconceived plan. There is no doubt that this plan (Table B) was not so successful in producing a chronic thiamin deficiency as it might have been, for as it turned out the reduction in thiamin was too drastic. In the other chronic thiamin deficiency experiments, published in the earlier paper, but performed in point of time later than the present ones, better control was attained of the degree and duration of the deficiency by giving each individual rat personal attention, and by ringing the changes between

TABLE B ADMINISTRATION OF THIAMIN

\begin{tabular}{c|c}
\hline Week & Thiamin Hydrochloride $(\mu \mathrm{g})$. \\
\hline 1 & 5 daily \\
2 & none \\
3 & 5 daily \\
4 & none \\
5 & 5 every other day \\
6 & same \\
7 & 2 every other day \\
8 & same \\
9 & none \\
10 & 2 daily \\
11 & none \\
12 & start again \\
\hline
\end{tabular}
$0.25,0.5$, and $1 \mathrm{ml}$. thiamin (minimal) according to its appetite. $0.25 \mathrm{ml}$. (about $2 \mu \mathrm{g}$.) was given daily first of all, and then at the first signs of anorexia, the dose was raised to $0.5 \mathrm{ml}$. Very rarely, $1 \mathrm{ml}$. was required to bring back the appetite; as soon as the rat resumed eating its entire daily feed, the dose was dropped again to $0.25 \mathrm{ml}$. In Experiments 3 and 4 described here, however, the plan was carried out.

Administration of Riboflavin.-The daily dose of riboflavin was $0.3 \mathrm{mg}$. When excluded, for reasons that will be obvious later, it was excluded altogether.

Stock Diet.*-The diet of choice, designated as STOck, was therefore as follows:

\begin{tabular}{lccccccc|} 
Casein $\ldots$ & $\ldots$ & $\ldots$ & $\ldots$ & $\ldots$ & $\ldots$ & $\ldots$ & 15 \\
Salt Mixture & $\ldots$ & $\ldots$ & $\ldots$ & $\ldots$ & $\ldots$ & $\ldots$ & 4 \\
Glucose $\ldots$ & $\ldots$ & $\ldots$ & $\ldots$ & $\ldots$ & $\ldots$ & $\ldots$ & 70 \\
WSV (synthetic water-soluble vitamins) & $\ldots$ & $\ldots$ & 10 & 100 \\
FSV (synthetic fat-soluble E in cod liver-oil) & & $\ldots$ & $6-10$ drops
\end{tabular}

\section{Histological Techniques}

Fixation was performed within 10 minutes of death,immediately after the final heart-rate recording, and the last weighing. There is danger that autolysis simulating neuronal disease will occur in rat brains and eyeballs, especially the latter, when left unfixed for longer than this (Rodger, 1953). Nissl, Giemsa, triple, Marchi, Weigert-Pal, Loyez, silver nitrate, and polarized light were the techniques employed.

\footnotetext{
- Fuller details may be found in the earlier publication (Rodger, 1953).
} 


\section{Plan of Experiments}

(1) Acute deficiency of thiamin due to administration of the analogue, combined with ariboflavinosis.

(2) Chronic deficiency of riboflavin.

(3) Chronic deficiency of thiamin on a high carbohydrate diet.

(4) Experiments 2 and 3 combined.

\section{Results}

(1) Acute Thiamin and Riboflavin Deficiency (Table I).

Duration.-19 days.

Diet.-Stock, less thiamin and riboflavin $15 \mathrm{~g}$.

Pyrithiamin (Merck) $100 \mu \mathrm{g}$.

TABLE I

EXPERIMENT 1

\begin{tabular}{c|c|c|c|c|c|c|c}
\hline \multirow{2}{*}{ Rat No. } & \multicolumn{3}{|c|}{ Weight (g.) } & \multicolumn{2}{|c|}{ Heart Rates (beats/min.) } & \multicolumn{1}{c|}{$\begin{array}{c}\text { Day } \\
\text { killed }\end{array}$} \\
\cline { 2 - 6 } & Initial & Final & Difference & Initial & Final & Difference & \\
\hline 1 & 80 & 87 & +7 & & & & 19th \\
2 & 75 & 70 & -5 & 500 & 300 & -200 & 19th \\
3 & 70 & 72 & +2 & 480 & 250 & -230 & 19th \\
4 & 80 & 77 & -13 & 500 & 220 & -280 & 19th \\
5 & 90 & 79 & -11 & 5 th \\
6 & 85 & 95 & +10 & & & & 19th \\
\hline
\end{tabular}

Clinical Behaviour.-On the 16th day all the rats became anorexic, leaving about a third of their daily ration. This is strongly suggestive in acute thiamin deficiency that the end is not far off. 3 days later, they ate nothing, spasticity of the hind legs was present in them all, even those which had gained a little weight, and Rats 3 and 4 fell over sideways on the inspection table, quite unable to stand (Fig. 1). The characteristic convulsive seizure occurred while picking up Rat 1 . Spontaneous convulsions occurred in Rat 3 while the remaining rats were being weighed. Rat 6 was the strongest of the group,

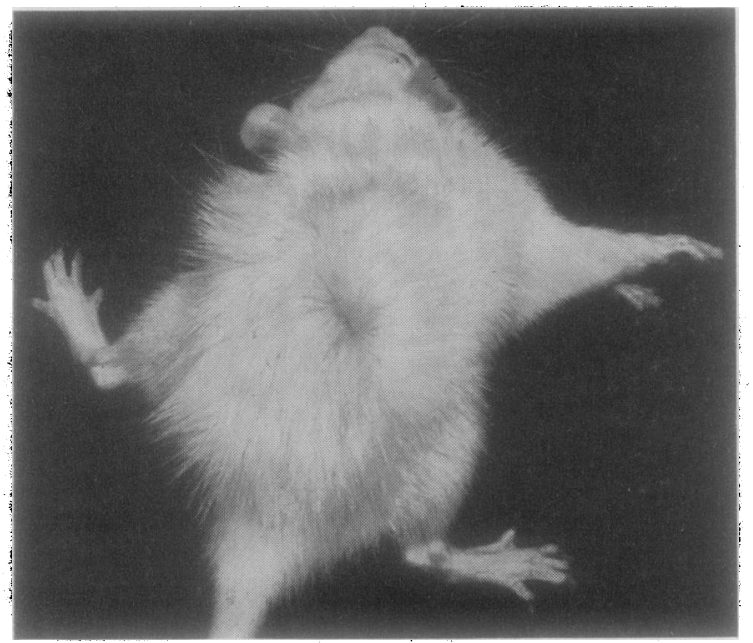

Fig. 1.-Albino rat suffering from acute deficiency of thiamin and ribofiavin in state of collapse $48 \mathrm{hrs}$ before death. The attitude is characteristic. 
but was killed with the others, as it was obviously moribund. No lesions of the corneae, skin, fur, or mucous membrane were found.

Pathological Observations.-No abnormalities of the visual pathway were found. Some of the twigs of the sciatic nerves which had been taken revealed degeneration of myelin with Marchi and with polarized light. Others were healthy. This observation agreed with those previously obtained in acute thiamin deficiency by itself (Rodger, 1953).

(2) Chronic Riboflavin Deficiency (Table II and Fig. 12, p. 152).

Duration. - 220 days.

$$
\begin{array}{cc}
\text { Diet.-Stock, less riboflavin } & 15 \mathrm{~g} . \\
\text { Thiamin (full) } & 500 \mu \mathrm{g} .
\end{array}
$$

Clinical Behaviour.-Here, with total absence of riboflavin from the diet, three of the group died by the 52nd day. By an unhappy coincidence, all three died in the early hours of the morning, and the pathological material had to be discarded, as the cadavers were discovered too late. This did not happen in any other experiment, and precautions were afterwards taken against such wastage. The three rats which so died, Nos. 3, 4, and 6, gained weight slowly during the first 3 weeks, but thereafter went downhill steadily, and became apathetic and bedraggled. At death, there was corneal neovascularization, hyperaemia of the nasal mucous membranes, and marked abdominal alopecia.

The other five rats continued to remain in moderately good health until the 160th day, when Nos. 1, 2, and 5 were killed (prematurely as is now seen to be the case). Rats 7 and 8 , the most active of the group, lived happily although quietly for another 2 months, and were quite strong when killed then. It is presumed all the survivors of the initial phase were able to manufacture their own riboflavin, sufficient to keep them alive in moderate health, although as it will be seen all showed signs of chronic riboflavin deficiency. Swelling of the nasal and labial mucosa was marked, these mucous membranes being fiery red in addition. "Dandruff", abdominal alopecia, and " spectacle ring" alopecia of the orbital regions were also marked. Neither corneal neovascularization nor cataract was seen.

Pathological Observations.-No abnormalities were found in the visual pathways of any of these rats.

TABLE II

EXPERIMENT 2

\begin{tabular}{c|c|c|c|c|c|c|c}
\hline \multirow{3}{*}{ Rat No. } & \multicolumn{3}{|c|}{ Weight (g.) } & \multicolumn{2}{c|}{ Heart Rates (beats/min.) } & \multicolumn{2}{c}{$\begin{array}{c}\text { Day } \\
\text { killed }\end{array}$} \\
\cline { 2 - 6 } & Initial & Final & Difference & Initial & Final & Difference & \\
\hline 1 & 85 & 130 & +45 & 500 & 400 & -100 & 160th \\
2 & 65 & 140 & +75 & 550 & 420 & -130 & 160 th \\
3 & 75 & 75 & - & 500 & - & - & 52 nd \\
4 & 80 & 70 & -10 & 500 & - & - & 45 th \\
5 & 80 & 150 & +70 & 500 & 420 & -80 & 160th \\
6 & 75 & 65 & -10 & 500 & - & -90 & 220th \\
7 & 72 & 180 & +108 & 500 & 410 & -90 & 220th \\
8 & 85 & 183 & +98 & 510 & 430 & -80 & \\
\hline
\end{tabular}

(2A) Paired Control to Above (Fig. 12, p. 152).

Diet.-Same plus $0.08 \mathrm{mg}$. riboflavin daily. Normal behaviour, appearance, and histology in all rats. 
(3) Chronic Thiamin Deficiency, associated with High Carbohydrate DiET (Table III and Fig. 12, p. 152).

Duration.-85 days.

Diet.-Stock, less thiamin $15 \mathrm{~g}$. Thiamin (minimal) (See Table B).

Clinical Behaviour.-On the 35th day, the first signs of anorexia appeared in Rats 1 and 2. A fortnight later, wasting, lassitude, inco-ordination, and bedraggling were present in the entire group. On the 75th day, Rats 1 and 2 were found to be spastic when placed on the inspection table, while the others were almost so. As all the rats were going downhill rapidly and it was difficult to improve the appetites, the experiment was concluded within the next 10 days. Rats 3,4 , and 5 were the last to become spastic and be sacrificed. This was, as indicated in the introduction, a subacute rather than a chronic deficiency.

TABLE III

EXPERIMENT 3

\begin{tabular}{c|c|c|c|c|c|c|c}
\hline \multirow{2}{*}{ Rat No. } & \multicolumn{3}{|c|}{ Weight (g.) } & \multicolumn{2}{c|}{ Heart Rates (beats/min.) } & \multicolumn{1}{c}{$\begin{array}{c}\text { Day } \\
\text { killed }\end{array}$} \\
\cline { 2 - 7 } & Initial & Final & Difference & Initial & Final & Difference & \\
\hline 1 & 95 & 87 & -8 & 500 & 360 & -140 & 75th \\
2 & 77 & 65 & -12 & 500 & 300 & -200 & 78th \\
3 & 80 & 81 & +1 & 500 & 360 & -140 & 85th \\
4 & 82 & 72 & -10 & 500 & 420 & -80 & 85th \\
5 & 85 & 83 & -2 & 500 & 300 & -200 & 85th \\
6 & 107 & 77 & -30 & 480 & 360 & -120 & 75th \\
\hline
\end{tabular}

Pathological Observations.-Rats 1 and 5 exhibited signs of degeneration in the visual pathway of significant degree. The nerve fibres in nerve and tract were swollen and tortuous and varicose, although not grossly (Figs 2 and 3). Many long oligodendrocytic chains were present. The sheaths showed granular isotropism and swelling of the nodes with polarized light (Fig. 4), but Marchi bodies were only just significantly increased. This indicates of course that the lesion was in an early state. In the dorsal nucleus there were a few scattered sclerosed cells, all of which were hyperchromatic. The appearance of these cells suggested central chromatolysis, but as this was also present in the pair-fed animals, one concludes it is an artefact (Fig. 5). There was a slight degree of satellitosis. The retina was not affected.

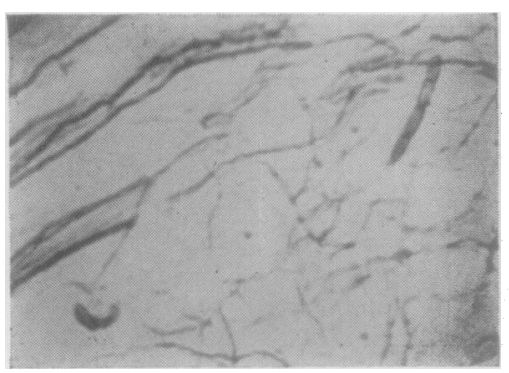

FIG. 2.-Normal visual fibres. Nerve fibres of optic tract seen spreading out through dorsal nucleus of lateral geniculate body. Author's silver, not counterstained. $\times 350$.

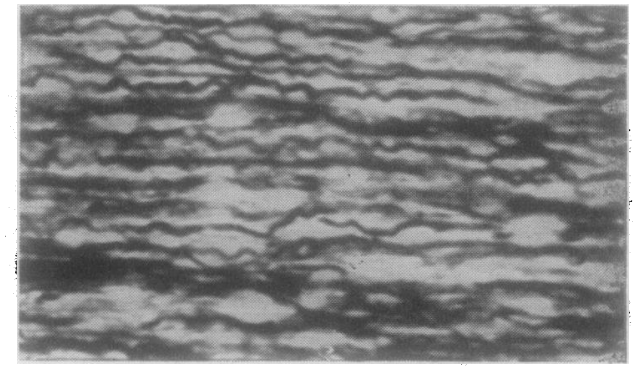

FIG. 3.-Tortuous nerve fibres in optic tract in subacute thiamin deficiency. Although the lesion is not gross, it is distinctive even at this stage. Author's silver. $\times 500$. 


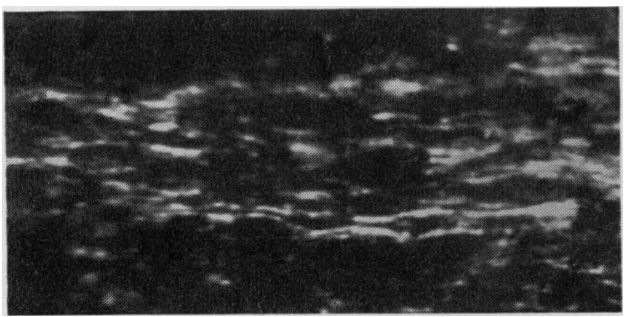

FIG. 4.- Swelling of nodes of Ranvier and granular isotropism in optic nerve. A case of chronic thiamin deficiency. Diameter of optic fibres more than $2 \frac{1}{2}$ times less than that of sciatic fibres, and therefore very difficult to photograph. Polarized light. $\quad \times 200$

FIG. 5.-Hyperchromatic sclerosed visual cell body in chronic thiamin deficiency. Central chromatolysis of other cells considered to be artefact. Giemsa. $\times 700$.

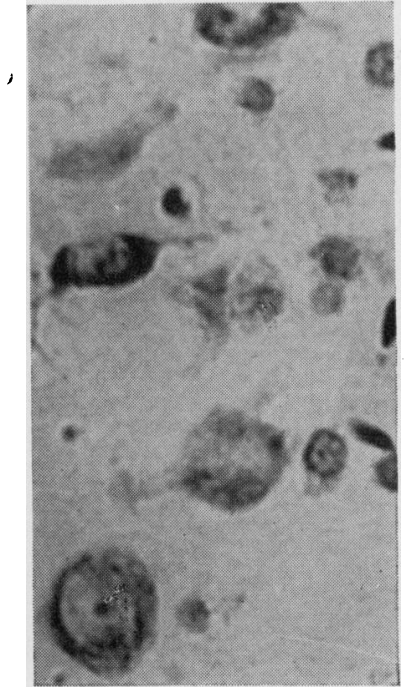

(3A) Paired Control to Above (Fig. 12).

Diet.-Same plus thiamin (full). Normal behaviour and histology in all rats.

(4) Chronic Thiamin and Riboflavin Deficiency (Table IV and Fig. 12).

Duration.-200 days.

Diet.-Stock, less thiamin and riboflavin $15 \mathrm{~g}$. Thiamin (minimal)

(See Table B).

Clinical Behaviour.-The first four rats in this group were litter mates of those in Experiment 3, which became moribund after 75 days on a thiamin diet similar to the present one. In this group, surprisingly, the rats continued to live in moderately good health, and to grow, although at a reduced rate, long after their brothers of Experiment 3 had expired. The only difference between the two diets, it should be noted, is that in Experiment 4 no riboflavin is included.

All eight rats of this group ate well, and never appeared hungry, even when their weight had greatly increased. Their appetites were less voracious than those of the paired controls. After the 35th day they became noticeably listless, spending much time sleeping during the

TABLE IV

EXPERIMENT 4

\begin{tabular}{|c|c|c|c|c|c|c|c|}
\hline \multirow{2}{*}{ Rat No. } & \multicolumn{3}{|c|}{ Weight (g.) } & \multicolumn{3}{|c|}{ Heart Rates (beats/min.) } & \multirow{2}{*}{$\underset{\text { killed }}{\text { Day }}$} \\
\hline & Initial & Final & Difference & Initial & Final & Difference & \\
\hline $\begin{array}{l}1 \\
2 \\
3 \\
4 \\
5 \\
6 \\
7 \\
8\end{array}$ & $\begin{array}{l}85 \\
75 \\
85 \\
80 \\
75 \\
85 \\
77 \\
75\end{array}$ & $\begin{array}{l}145 \\
100 \\
107 \\
142 \\
138 \\
150 \\
140 \\
145\end{array}$ & $\begin{array}{l}+60 \\
+\quad 25 \\
+22 \\
+62 \\
+63 \\
+65 \\
+63 \\
+70\end{array}$ & $\begin{array}{l}500 \\
500 \\
500 \\
500 \\
500 \\
500 \\
500 \\
500\end{array}$ & $\begin{array}{l}360 \\
360 \\
320 \\
340 \\
380 \\
360 \\
365 \\
330\end{array}$ & $\begin{array}{l}-140 \\
-140 \\
-180 \\
-160 \\
-120 \\
-140 \\
-135 \\
-170\end{array}$ & $\begin{array}{l}\text { 160th } \\
130 \text { th } \\
100 \text { th } \\
160 \text { th } \\
160 \text { th } \\
160 \text { th } \\
200 \text { th } \\
200 \text { th }\end{array}$ \\
\hline
\end{tabular}




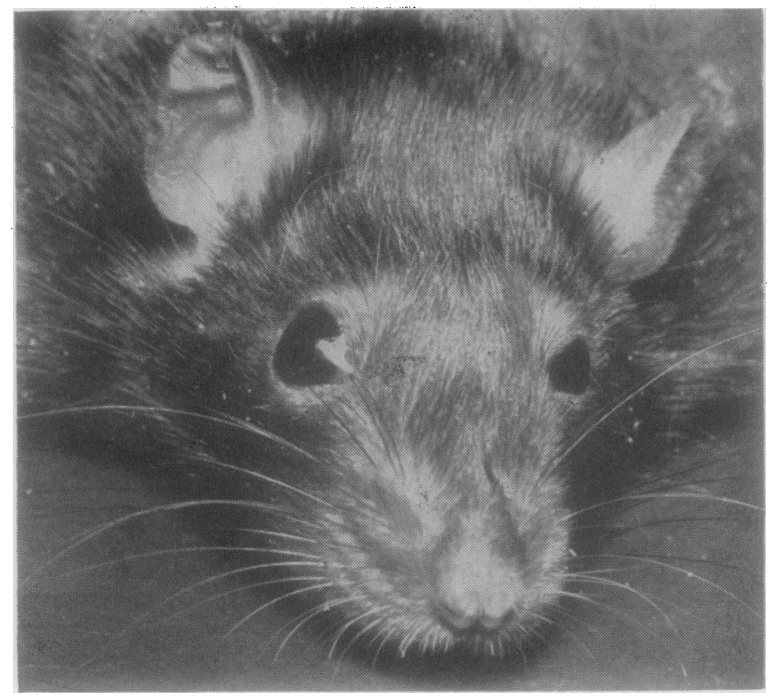

Fig. 6.-Spectacle-ring alopecia, dandruff, and swelling of nasal mucosa in chronic thiamin-riboflavin deficiency. (Rat is a hooded white).

Fig. 7.-Same as Fig. 6, side view.

day. When roused, they proved quite active for short periods, running round the examination table like healthy rats, but they were never seen doing this in the cages. On the 56th day, alopecia was seen to commence around the eyes. Abdominal alopecia commenced insidiously. A closer search than usual on the 140th day revealed that all the rats had a degree of abdominal alopecia; well demarkated " spectaclering" alopecia, many small white scales on the fur (dandruff), and red swollen lips and nostrils (Figs 6 and7) were also noted. This was still the picture

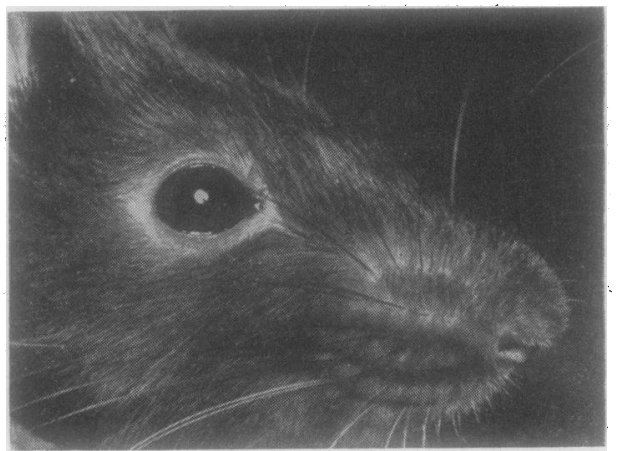
on the 160th day, by which day all the rats save Nos. 7 and 8 were killed. The appearance of the last two was unaltered when the experiment was completed 40 days later.

Pathological Observations.-Changes were seen in all the rats killed on or after the 160th day. These appear to be highly significant, except in the retinae. Vacuolation and cloudy swelling of the ganglion and bipolar cells of the retina we have been unable to exclude entirely from healthy retinal tissue. No other pathological change being seen, it was considered that no retinal lesion existed. The changes occurring in the rest of the visual pathway were as follows: thick clustered oligodendrocytic chains (a customary finding in all these deficiency experiments); swollen, varicose, and tortuous visual fibres, with some fragmentation centrally; myelin sheaths grossly destroyed in Rats 1,4 , and 8 , and demyelinization present in all, diffuse, patchy, and with many plaques; the geniculate cells in all were hyperchromatic and sclerosed as a rule, but not invariably so, as had been the case in the previous experiments (Rodger, 1953). Satellitosis was present, and here and there neuronophagia could be seen (Figs 8, 9, 10, and 11, opposite).

The sciatic nerves revealed advanced demyelinization with Weigert-Pal, but as in Experiment 1, not in every twig, for some twigs were healthy throughout. Unlike Experiment 1, the peripherally placed nerve bundles only were affected. 


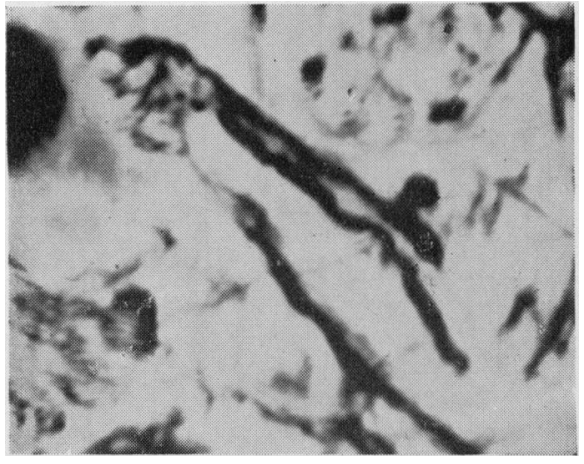

FIG. 8.-Swelling of terminations of optic tract fibres within dorsal nucleus in chronic thiamin-riboflavin deficiency. Note Held endings above synapsing on final neurone cell body. Author's silver. $\times 1,275$.

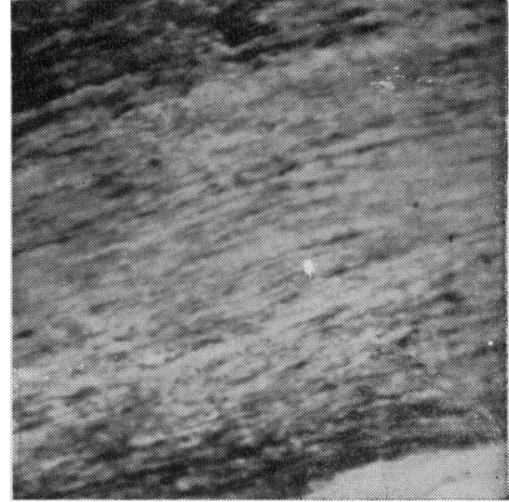

FIG. 9.-Large plaque of demyelinization in intracranial portion of optic nerve in chronic thiamin-riboflavin deficiency. Weigert-Pal. $\times 650$.

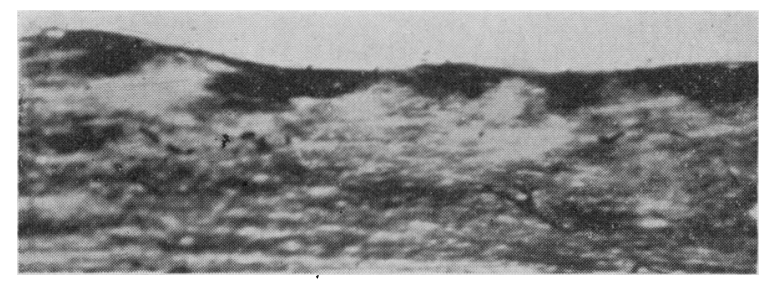

Fig. 10.-Old patchy demyelinization of optic tract in chronic thiamin - riboflavin deficiency. Loyez. $\times 200$.

FIG. 11. - Hyperchromatic sclerosed cells in dorsal nucleus in chronic thiaminriboflavin deficiency. Note also satellitosis and neuronophagia on right. Giemsa. $\times 400$.

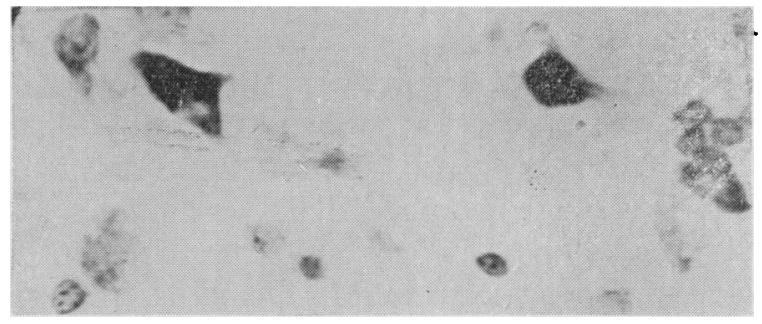

(4A) Paired Control to Above (Fig. 12, overleaf).

Diet.-Same plus riboflavin and thiamin (full).

These rats developed normally, the heart rates dropping slightly, and only as they gained weight. The visual pathways exhibited none of the lesions found in the corresponding deficiency group.

\section{Discussion}

It is interesting to compare the pathologies of the chronic thiamin deficiency group (Rodger, 1953) with the combined thiamin-riboflavin deficiency group in the present study. These two experiments compare more favourably in point of time than does the so-called chronic thiamin deficiency described here with the combined. In the thiamin deficiency of longer duration (180 days), the lesions were much more marked than those found in the thiamin deficiency of 75-85 days (Experiment 3), as might be expected; thus 


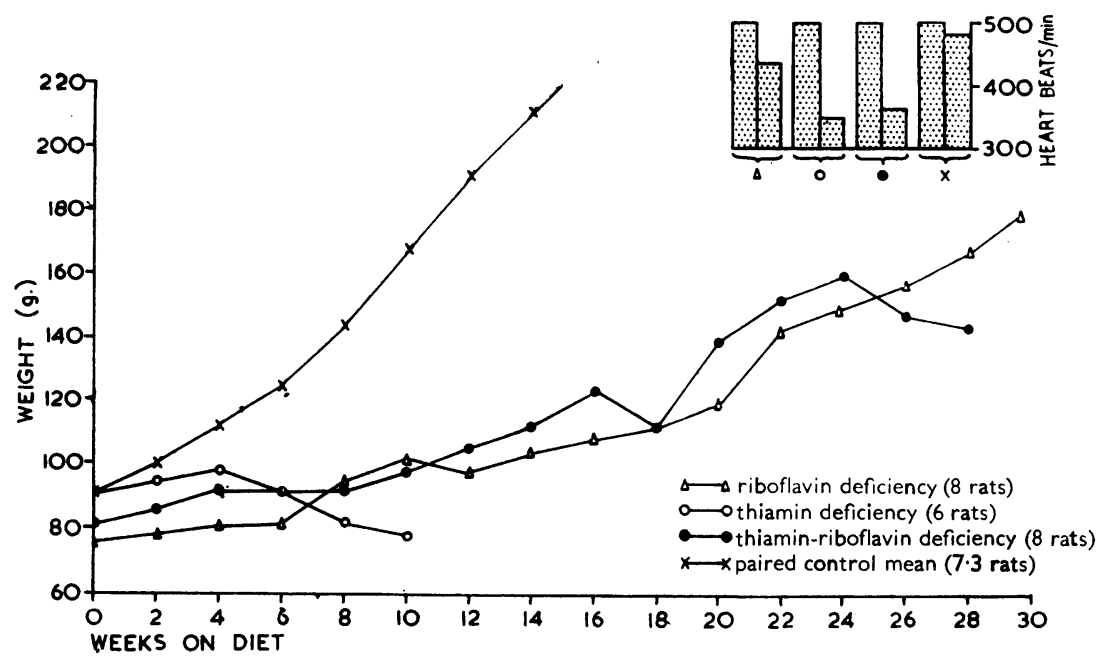

FIG. 12.-Average weight curves and heart rates (start and finish). Experiments

2,3 , and 4 , with pair-fed control groups taken as one.

the latter is probably better designated as subacute. In prolonged thiamin deficiency, the fibres of the optic nerve and tract are distorted, swollen, varicose, and tortuous, the endings being enlarged, sometimes fragmented, and argyrophil ring-shapes much increased; long oligodendrocytic chains parallel with the myelin sheaths are present; the sheaths reveal diffusely scattered demyelinization, especially in the tract, and many grey and white plaques. The final visual neurones-the cell bodies and an occasional axis cylinder whose continuity with the cell body has not been severed-also take part in the process of degeneration; the cells are almost all sclerosed and deeply hyperchromatic, their processes swollen to nearly twice the natural size; neuronophagia and satellitosis completes this picture of a severe lesion. It is not possible to dissect out the optic radiations in the rat, but one presumes the changes found up to and including the start of the final visual neurone will be reflected throughout what little remains of the visual pathway. The lesions just described seem to be the obvious end-results of those found in the subacute group. How do they compare with the lesions found in the combined chronic deficiency of thiamin and riboflavin, the duration of each experiment being so nearly the same?

The nerve fibre distortions in nerve and tract are almost identical; the central terminations in the combined deficiency are not so grossly affected, but this is the only difference. The myelin changes are also almost similar, ballooning, irregularity of 'outline, diffusely scattered plaques, and many demyelinized patches being common to both groups. Although the lesions in the dorsal nucleus of the lateral geniculate body affecting the final visual neuron are not so gross in the combined deficiency, the changes which exist are in essence the same. In neither experiment were retinal changes significant.

Why these minor differences occur, if in fact they are differences, it is 
impossible to say. It could be a highly significant observation, or no more than the sort of variation one is likely to find in short experimental series such as those described, even though more histological techniques than is usual were employed, with a corresponding increase, it is believed, in the accuracy of the observations.

Zimmerman (1943) states that in the dog twice the length of time is required to produce degeneration of the nervous system by riboflavin than by thiamin deficiency. On these premises we might conclude that Experiment 2 (220 days) did not last long enough. In short, it is dangerous to conclude from this one experiment that a riboflavin deficiency does not lead to degeneration of the visual neurons. Krukowska (1951) kept rats on a diet deficient in riboflavin for about 550 days. In the end they lost weight, and became almost bald. Unfortunately, he does not seem to have examined the visual pathway, and recorded changes in the anterior segment of the eyeball only: neovascularization, round-cell infiltration of the superficial and deep corneal layers, and cataract. These signs were first observed at the eighth week, so should have been present in the rats of Experiments 2 and 4. Some were observed, but not all. Cataract was absent from the list, although a degree of it might have been present, no ophthalmoscope being employed. There is sufficient in common, nevertheless, between Krukowska's and the present experiments to confirm the belief that in Experiments 3 and 4 a state of chronic ariboflavinosis had been attained.

The deficiency in thiamin, especially in the earlier study, forms an excellent "cross control" for the combined thiamin-riboflavin deficiency experiment. There can be no doubt that, in addition to chronic riboflavin deficiency, the rats of Experiment 4 were suffering from thiamin deficiency, the high degree of bradycardia being one indication of that (Fig. 12). It seems likely that, though these deficiencies were combined, it was the lack of thiamin which was responsible for the lesions described. Thiamin deficiency was the outstanding clinical feature in both groups; moreover, the pathological changes found in the combined deficiency group reflected almost exactly those found in the thiamin deficiency group, and no such changes existed in the riboflavine deficiency group. That the changes in each group were significant is proved by their total absence in the pairfed rats of the control groups.

The histology of the skin and mucous membranes was not studied, but it should be mentioned that no macroscopic lesions referable to these tissues were observed other than the scaly dermatitis (described above as "dandruff") and the swelling of the naso-labial mucosa. These changes were certainly due to the riboflavin deficiency. Pyridoxine was administered at the comparatively high level of $0.08 \mathrm{mg}$. daily. Many workers give only $0.01 \mathrm{mg}$. without lesions developing. Sinclair (1952) from his own experiments, drew attention to the cutaneous lesions found in pyridoxine and fat deficiency, a fact which was unknown to the writer when these experiments were started 
in 1950. Nevertheless, the supply of essential fatty acids, as well as of pyridoxine, would appear to have been ample. In a total of nearly 200 thiamin deficient rats examined during the last few years, true acanthosis and hyperkeratosis was never observed, although slight degrees of it might have been missed in the early stages.

If these experiments, visual data apart, do nothing else, they lend support to the belief held by many biochemists that when thiamin deficiency is combined with that of riboflavin or of any other respiratory-enzyme vitamin, the requirement for thiamin is greatly reduced. This seems to have been the case in Experiment 4, in which all the rats outlasted the rats of Experiment 3, although the degree of thiamin deficiency was the same in each. The rats of Experiment 4 lived more than twice as long as the others, in a better state of health, and might still be alive, if they had not been killed. This may be because in the combined deficiency the metabolism was made to depend more upon fat. Interaction and interdependence between the different members of the vitamin B complex is believed to occur; they are probably all capable of forming different enzyme systems with different proteins according to circumstances.

Though there must be fallacies in any argument based on conclusions reached by animal experimentation, the results here obtained seem to support the theory that when the B vitamins are deficient and the diet is high in carbohydrates (a state of affairs mercifully extremely rare, even in time of famine) it is the lack of thiamin which is directly responsible for the amblyopia. This is still partly conjectural, as so many factors are involved, but there is a parallel in the observation by Zimmerman (1943) that thiamin often evokes a response in the early treatment of pellagra, where niacin fails, although both may have been deficient.

These arguments suggest that it might be wiser as a routine procedure when treating nutritional amblyopia to give thiamin and a well-adjusted diet not too rich in the other vitamins or in protein, rather than a "blunderbuss" therapy incorporating every known and imagined vitamin preparation. Treatment of the latter kind did not prevent a further loss of sight (from partly-blind to fully-blind) in almost one-third of 238 cases of nutritional amblyopia resulting from the last war (Rodger, 1952). After the high promise of better things which these patients rightly expected, the loss of what little vision remained to them must have been a bitter blow.

The sciatic nerve changes about which there is so much controversy are recorded without comment for the benefit of those interested.

\section{Summary}

(1) Three groups of rats were fed a high carbohydrate diet. In one group, thiamin was administered at an inadequate level; in a second, riboflavin was withheld; and in the third, the diet was made deficient in both these vitamins to the same degree. 
(2) The thiamin deficient rats died at the end of 75-85 days; some of the riboflavin deficient rats which were apparently able to manufacture a little of the vitamin symbiotically were still alive at the end of 220 days; and the thiamin-riboflavin deficient lived up to 200 days, when the experiment was terminated.

(3) Slight signs of degeneration were found in the visual pathways of the thiamin deficient; none in the riboflavin deficient; and gross changes in the thiamin-riboflavin deficient. Control rats on isocaloric diets with full vitamin supplements were not affected.

(4) A fourth series of rats made acutely deficient in thiamin (by administration of the analogue) and in riboflavin showed no signs of degeneration in the visual pathways.

(5) It is concluded that prolonged thiamin deficiency with a predominantly carbohydrate diet leads to optic atrophy; when riboflavin is deficient in addition, the animal lives longer-for reasons not yet fully understood-and the thiamin deficiency is even more prolonged, so that the lesions involving the visual pathways become grosser still.

(6) The findings are briefly referred to human nutritional amblyopia.

This work was made possible by a grant from the King's College Medical School, University of Durham, and the photomicrographs are reproduced with the permission of the Director of the Photographic Department. I am grateful to Mr. Robert Watt for technical assistance.

\section{REFERENCES}

KRUKOWSKA, I. K. (1951). Klin. oczna, 21, 113.

RODGER, F. C. (1952). Arch. Ophthal. (Chicago), 47, 570.

- (1953). British Journal of Ophthalmology, 37, 11.

Sinclair, H. M. (1952). "Lipid Metabolism". Biochem. Soc. Symp., No. 9, p. 80.

Zimmerman, H. M. (1943). "The Role of Nutritional Deficiency in Nervous and Mental Disease". Res. Pübl. Ass. nerv. ment. Dis., 22, 51 and 75. 